\title{
Natural/sexual selection: What's language (evolution) got to do with it?
}

\author{
Ljiljana Progovac \\ Wayne State University \\ progovac@wayne.edu
}

\begin{abstract}
By considering a specific scenario of early language evolution, here I advocate taking into account one of the most obvious players in the evolution of human language capacity: (sexual) selection. The proposal is based both on an internal reconstruction using syntactic theory, and on comparative typological evidence, directly bringing together, formal, typological, and evolutionary considerations. As one possible test case, transitivity is decomposed into evolutionary primitives of syntactic structure, revealing a common denominator and the building blocks for crosslinguistic variation in transitivity. The approximations of this early grammar, identified by such a reconstruction, while not identical constructs, are at least as good proxies of the earliest stages of grammar as one can find among tools, cave paintings, or bird song. One subtype of such "living fossils" interacts directly with biological considerations of survival, aggression, and mate choice, while others clearly distinguish themselves in fMRI experiments. The fMRI findings are consistent with the proposal that the pressures to be able to master ever more and more complex syntax were at least partly responsible for driving the selection processes which gradually increased the connectivity of the Broca's-basal ganglia network, crucial for syntactic processing, among other important functions.
\end{abstract}

Keywords: Evolution of grammar/syntax; (sexual) selection; decomposition of transitivity; Broca's-basal ganglia network; (verbal) aggression.

\section{Introduction: Regarding adaptationism and selection ${ }^{1}$}

Much of current research on language evolution reveals a distaste, if not disdain, for proposals invoking natural/sexual selection when it comes to lan-

\footnotetext{
${ }^{1}$ For a memorable, outstanding conference experience, I am thankful to the superb PLM 2018 audience and participants, as well as organizers, especially Katarzyna Dziubalska-Kołaczyk.
} 
guage capabilities, and cognitive capabilities more generally. There are claims to the effect that humans have stopped selecting altogether, except perhaps for some minor health benefits (e.g. Bickerton 2007: 511). Chomsky (2002) considers that natural selection is messy and not properly understood, and that the evolutionary explanations that invoke natural selection e.g. via gradual tinkering can be symptomatic of the lack of understanding: "if you take a look at anything that you don't understand, it's going to look like tinkering" (139), and when things are properly understood, one realizes that there is much more order in nature." 2 This distaste for adaptationism and selection is evident not only in Noam Chomsky's long-held views on language evolution, but also in some recently advanced cultural evolution approaches to language. According to e.g. Steels' (2011) review, adherents to cultural evolution consider that language features per se do not originate through genetic evolution, and are not linked to biological fitness. These two approaches cannot be more different in their methodologies and theoretical orientation, and yet they often converge on the same assumption that natural/sexual selection is not (directly) relevant for language (evolution). Nonetheless, selection is the most obvious mechanism to explore when it comes to determining how the genetic basis specifically for language came to be, and the one without which no proposal is complete.

Sexual selection has been repeatedly invoked in the studies of human evolution, including in the recently postulated self-domestication hypothesis, which invokes selection against (physical) aggression, and in favor of prosociality and pair-bonding, considered to be beneficial for child rearing (e.g. Hare et al. 2012; Stanyon and Bigoni 2014; Okanoya 2015; Gleeson 2018). ${ }^{3}$ Likewise, relating specifically to language, the emergence of early grammars has been attributed to sexual selection, especially in the context of their utilization for insult and verbal aggression (Progovac and Locke 2009; Progovac 2015, 2016a). Progovac and Benítez-Burraco (2019) crossfertilize these two approaches by seeking synergy between the gradual reduction in physical aggression under the self-domestication hypothesis, and the gradual emergence of verbal aggression under the early grammar hypothesis, leading to a

\footnotetext{
${ }^{2}$ This contrasts with e.g. Dediu's (2015: 131) view, which embraces "the messiness but also elegance that are expected of products of biological evolution."

${ }^{3}$ It is important to point out here that, paradoxically perhaps, even prosociality and the cooperative aspects of human behavior would have been enhanced through competition and selection.
} 
more precise, and more motivated proposal regarding human evolution. Darwin's (1874) view was that language evolved gradually through sexual selection, as an instinct to acquire a particular method of verbal display similar to music (see also Fitch 2010 for recent arguments for musical protolanguage). Darwin also considered that the first human utterances were somewhat continuous with animal calls in that they were strongly emotional, expressing lust and hostility.

Human mate choice even today is often influenced by displays of cognitive abilities, through the use of language (e.g. Miller 2000; Franks and Rigby 2005). Rightly or wrongly, we often consider eloquence to be correlated with intelligence, and the most eloquent speakers tend to have the highest status (e.g. Locke 2009), even in modern societies, which in turn is correlated with greater reproductive success (Tallerrman 2013: 95). Darwin's (1874) characterization of sexual selection includes two processes, in a sense two sides of the same coin: mate choice and aggressive rivalry (see also Miller 2000; Hill et al. 2017). Franks and Rigby (2005) have performed experiments which found that males increase their creativity with language both in the presence of attractive females and in the presence of male competitors, providing some evidence that males even today display their creativity and cognitive skills by using language, and that they continue to compete with other males in this respect.

\section{The Five Problems/challenges facing language evolution research}

Here I clarify the nature of the problems encountered in language evolution research, as well as offer a way to begin to tackle those problems. According to Progovac (2019a), there are (at least) five interlocking components (The Five Problems), i.e. challenges for any account of language evolution:

(1) (i) The Decomposition Problem, i.e. identification of the initial stage(s) of language.

(ii) The Selection Problem, i.e. how the genetic basis for language came to be.

(iii) The Loop Problem, i.e. the language-brain-genes linkage.

(iv) The Variation Problem, i.e. compatibility with the parameters of language variation and change. 
(v) The Theoretical Grounding Problem, i.e. grounding in linguistic theory and analysis.

Of these, the most difficult challenges are posed by (i) The Decomposition Problem and (ii) The Selection Problem. Not only are these Problems extremely difficult to tackle, but they are also intertwined, exponentially increasing the difficulty. Especially when it comes to syntax, these problems are typically either avoided or denied altogether, in the proposals to the effect that syntax can neither be decomposed into primitives, nor can it be subject to selection (e.g. Berwick and Chomsky 2011; 2016). Attempts to do either are subjected to expressions of incredulity/disbelief, if not ridicule. ${ }^{4}$ Consider e.g. Lightfoot's (1991) response to Newmeyer's (1991) early suggestion that syntax can be subjected to gradual evolution, i.e. decomposed into evolutionary primitives. In particular, Newmeyer (1991) proposed that the principle of Subjacency (the principle taken to account for syntactic islands, i.e. constructions that prohibit Move) may be a later evolutionary development. Lightfoot (1991) response was that "subjacency has many virtues, but ... it could not have increased the chances of having fruitful sex."

This kind of response typically meets and greets any suggestion invoking decomposition of syntax into primitives/stages, or invoking selection as a mechanism for the evolution of grammar. The idea behind these responses is that syntax is so abstract, and so pure, and so inscrutable, that one cannot possibly subject it to some messy forces of selection or tinkering. Somehow, our failure to shed clarity on certain principles of syntax is taken as conclusive evidence that syntax is one single undecomposable block, which, as such, must have evolved as a result of one single, random mutation (e.g. Berwick and Chomsky 2011, 2016). There is also of course another logical possibility, which is that we (syntacticians) just got some things wrong.

In fact, what transpires upon closer scrutiny, is that the whole half-acentury enterprise surrounding in particular Subjacency has been misdirected, and that Subjacency cannot possibly be a principle of syntax. As discussed in e.g. Progovac $(2009,2015)$, constructions which prohibit Move (is-

\footnotetext{
${ }^{4}$ As noted by Fitch (2017b: 6), there is a tendency in language evolution research to "stoop to disparage alternative hypotheses with derogatory nicknames..., in the tradition initiated by Max Müller's 19th century attacks on Darwin (Müller 1861)." It is of interest for later discussion that insult and derogatory language seem to be alive and well, even in modern times, and even in academic discourse.
} 
lands) are many and various and do not form a natural class, while those that allow Move do form a natural class. If islands have no thread in common, then it is not surprising that, despite the sustained effort for half a century (since Ross 1967), to date there has been no unified or principled account of islandhood/Subjacency (Belletti and Rizzi 2000 report an interview with Chomsky, in which he concludes that much). Very simply put, the reason why Subjacency seems so inscrutable and pure (and thus not subject to evolution) is because it does not exist as a principle of syntax. ${ }^{5}$ This certainly gives one pause when it comes to other seemingly inscrutable principles of syntax. Are they inscrutable because that is just the nature of our language capacity, which arose through one single random mutation, or is their seeming inscrutability a sign of wrong analysis? The only way to know is to subject these principles to testing and falsification, both within and beyond linguistic theory, with the considerations of language evolution certainly taken into account.

While the particular track that Newmeyer proposed regarding Subjacency may have been in the wrong direction, it was a specific and syntactically informed proposal, and as such it provided a good basis for debate and subsequent proposals. For example, inspired by this proposal, Progovac (2009, $2015,2019 b$ ) proposed the opposite track, that Subjacency (lack of Move) is actually the primary, ancestral state of grammar, while Move was a later innovation (hence the default, elsewhere flavor of islandhood). ${ }^{6}$ Importantly, scientific progress cannot be made in the fields of language evolution and human evolution more generally without advancing testable and falsifiable hypotheses in the attempt to confront The Selection and The Decomposition Problems specifically relating to language, as language is the key player in human evolution. With that in mind, I offer a specific scenario (using specific linguistic data and analyses) where selection would have played a direct role in the evolution of (proto-)syntax. I also consider how tinkering with these

\footnotetext{
${ }^{5}$ Progovac (2019b and references cited there) argues that Subjacency as a syntactic postulate needs to be discarded from syntactic theory, and that islandhood should be considered as a default state of grammar, rather than a restriction on grammars. Subjacency poses insolvable problems and obstacles not only for linguistic theory, but also for language evolution research.

${ }^{6}$ This is the sense in which providing specific and falsifiable hypotheses, even if they turn out wrong, leads to new and more detailed proposals, which can be further tested. While this process may be painstaking, or plain painful, the alternative, which puts grammar on the pedestal of the inscrutable, and which operates with claims that cannot be falsified, is simply not scientific.
} 
early protostructures would have led to crosslinguistic variation in transitivity.

It is also important for me to point out that by looking at the evolution of (proto-)syntax in a natural selection framework, I am not claiming that other aspects of language are not just as important, or that cultural evolution is not just as important. In fact, the crux of my proposal is that these early forms of language/grammar arose as cultural innovations, innovations that proved beneficial enough to be subject to (sexual) selection. As also repeatedly pointed out by e.g. Fitch (2017a), we should by now be beyond the tired debates of nature vs. nurture, or culture vs. genes, simply because one needs both in order to shed light on language evolution (Section 3). Likewise, by focusing on the data that reveal relevance of insult and derogatory language, I am not claiming that cooperation is not just as important as competition, or that syntax arose exclusively for this purpose. In fact, there are many other uses of this proto-grammar that would have been extremely beneficial, including using simple combinations to name animals (rattle-snake) and plants (tumbleweed), as well as to issue simple commands (Rattle snake!) or statements (Snakes rattle.) (see e.g. Progovac 2016a). My proposal isolates one important factor, but there must have been multiple interacting factors giving rise to a phenomenon as rich, complex, and multi-layered as is human language. The scenario that imposes itself as highly relevant, upon a detailed consideration of certain "fossil" data, is the one that considers the potential for derogatory language and insult. This scenario is most directly related to human biology, including aggression and survival, as it reveals immediate reproductive advantages. It also directly ties into considerations of human self-domestication (Progovac and Benítez-Burraco 2019).

\section{Genes vs. culture?}

The processes involving culture and genes are interlocked and interwoven in a way that is well illustrated by considering the adaptation of lactose tolerance, as illuminated by Deacon's (2003) metaphors of masking and unmasking of pre-adaptations. Without having discovered the genetic basis that is responsible for lactose tolerance into adulthood, it would seem to us that this is not a big deal: farming, as well as enjoying milk and cheese, were cultural inventions, beneficial for humans, and they therefore spread (culturally) and found an important place in human nutrition, at least in those populations that engage in farming. So, it may seem to us that culture is sufficient here. 
Perhaps lactose tolerance can be attributed to "general good health" rather than to any specific genetic bias, on analogy to the claims that language abilities are based on "general cognitive abilities". But what is not obvious is that this cultural invention of enjoying dairy products set up the selection pressure for biological evolution. Now we know that this invention quietly "discovered"/"unmasked" the genes of those individuals who were genetically better predisposed to benefit from it, and the genetic variants of these individuals, and then their offspring, were gradually selected until their alleles reached almost $100 \%$ frequency in some places in Europe (Stone and Lurquin 2007; Fitch 2017a).

This adaptation is a good example of how culture (or environment) and genes often interact: there is already genetic variability among individuals in a population; a cultural invention takes place, and spreads (the cultural aspect of evolution). This innovation quietly "discovers" those individuals who are just a bit better able to profit from this innovation and propagates their genetic make-up, at the expense of others (the genetic aspect of evolution). This certainly does not mean that every single innovation leads to a selective sweep, but it does follow that some such innovations can and do lead to selection.

It is often claimed that the genetic basis for language was put into place by some other abilities/precursors, such as tool-making, and once these abilities were in place, language could simply emerge, ascribing to language an incredibly passive role in its own evolution. There is no a priori reason to believe that our brains are better adapted to tool making, vs. to using language; in fact, there is every reason to believe the opposite. It is important to emphasize here that whether or not e.g. tool-making provided a rough precursor or preadaptation for hierarchical syntax (see e.g. Toya and Hashimoto 2015), there still would have, or could have, been adaptation and selection for using specifically hierarchical syntax, and for fine-tuning language skills more generally. Pre-adaptation and selection are not distinct processes; in fact, a pre-adaptation, when it is re-purposed (unmasked), is again subject to selection for that new purpose (e.g. Deacon 2003). There is no reason why other cognitive abilities would be subject to selection/fitness, but not language features themselves. Words can be just as potent as tools. As pointed out in e.g. Bergen (2016: 7), the most potent words of all are in fact swear words and derogatory language, including taboo words, which "elicit the strongest measurable psychological reactions: the fastest pulse, the sweatiest palms, the shallowest breathing." This proposal takes such words into account. 


\section{Reconstruction of proto-grammar and common denominator for cross-linguistic variation}

My proposal is that human language reconstructs back to an intransitive (one argument) absolutive-like grammar, which provides the foundation and common denominator for crosslinguistic variation in the expression of e.g. transitivity (e.g. Progovac 2015, 2016a). This proposal is based both on an internal reconstruction using syntactic theory, and on comparative typological evidence, in an attempt to directly bring together, formal, typological, and evolutionary considerations. In this reconstruction, I decompose transitivity into evolutionary primitives of syntactic structure, addressing The Decomposition Problem, and identify a common denominator for crosslinguistic variation in transitivity, addressing also The Variation Problem.

But first things first: how do we hypothesize what the ancestral grammar was like, i.e. how do we address The Decomposition Problem? As per The Theoretical Grounding Problem, the reconstruction of this ancestral grammar needs to be theoretically informed, rather than impressionistic. To this end, I have used some influential and stable theoretical postulates adopted in Minimalism, as well as in its predecessors. This is certainly not the only framework that can be used for such reconstructions, as different linguistic frameworks tend to shed light on different aspects of human language. In this respect, the reconstruction of proto-grammar in e.g. Progovac $(2015,2016 \mathrm{a}$, 2019a), based on Minimalism, is synergistic with Heine and Kuteva's (2007) reconstruction of proto-vocabulary, based on grammaticalization, which reveals a stage in language evolution in which only nouns and verbs were used. As will be seen below, the syntactic reconstruction leads to a flat small clause stage which features a two-slot combination of just one verb and one noun. Considering reconstructions from additional frameworks may lead to further insights and hypotheses regarding the initial stages of grammar, and ideally to more converging results.

According to Minimalism and predecessors (e.g. Stowell 1981; Kitagawa 1985; Chomsky 1995; Adger 2003; Citko 2011), a modern clause/sentence is characterized by the following partial hierarchy of syntactic layers: ${ }^{7}$

\footnotetext{
${ }^{7}$ This is the most stable and insightful postulate in this framework, and the most useful one for language evolution considerations (see e.g. Progovac 2019b). I take this not to be accidental, given that the biological considerations of language evolution should be synergistic with theoretical linguistic considerations.
} 
(2)

$$
\mathrm{CP}>\mathrm{TP}>\mathrm{vP}>\mathrm{VP} / \mathrm{SC}
$$

The inner VP/SC (small clause) layer accommodates the verb/predicate and one argument (noun).

The little vP layer supports transitivity by accommodating an additional argument, such as agent. TP (Tense Phrase, or Sentence) layer accommodates the expression of e.g. tense and finiteness, etc. This theoretical construct, supported by abundance of linguistic evidence, offers a precise and straightforward method of (internally) reconstructing the initial syntactic stage(s) in evolution, i.e. the bottom intransitive small clause layer (Progovac 2015), which can accommodate only one argument. While the SC/VP can be composed without a little $\mathrm{vP}$ (transitivity) layer, the $\mathrm{vP}$ and $\mathrm{TP}$ can only be built upon the foundation of a SC/VP. One can thus reconstruct a vP-less and TPless (intransitive and tenseless) free-standing SC stage in the evolution of language. Some present-day approximations of this kind of grammar, which does not distinguish subjects/agents from objects/patients, are illustrated and discussed in Sections 5, 6 (fossil compounds) and Section 7 (fossil middles), together with some fMRI experiments supporting their characterization as fossils. The compositional semantics of this type of proto-grammar is given in Section 7.

Another advantage of reconstructing syntax into its (evolutionary) primitives is that such a reconstruction reveals how these primitives can be combined and recombined to produce exactly the three predominating transitivity types (e.g. Progovac 2016a; 2019a). With rare exceptions, transitive structures add just one extra piece to the foundational ancestral structure, whether from below (accusative) (3), or from above (ergative) (4), and serial verb patterns string together a limited number of intransitive clauses, often just two (5) (e.g. Aboh 2009).

(3a) Mary shook.

(3b) Mary shook him. (accusative)

Tongan (Tchekhoff's 1973: 283)

(4a) Oku ui 'a Mele

PRES call ABS Mary

'Mary calls.' / 'Mary is called.' 


$$
\begin{array}{llllll}
\text { Oku ui } & \text { 'e } & \text { Sione } & \text { 'a } & \text { Mele } & \text { (ergative) } \\
\text { PRES call } & \text { ERG } & \text { John } & \text { ABS } & \text { Mary } & \\
\text { 'John calls } & \text { Mary.' }
\end{array}
$$

Anyi-Sanvi, Niger-Congo (Van Leynseele 1975)

$$
\begin{aligned}
& \text { [cùá c̀i }] \quad[\underline{a ́ k j} \quad \underline{\text { !dì }}] \quad \text { (verb series) } \\
& \text { [dog catch }{ }_{\text {HAB] }} \text { [chicken eat] } \\
& \text { 'The dog ate the chicken.' }
\end{aligned}
$$

In this sense, each transitivity type tinkers a (slightly) different solution to the same problem, but does not start from scratch, but rather from the common foundation provided by the ancestral proto-grammar. This is consistent with François Jacob's (1977) proposal that evolution's creative force lies in tinkering with the existing, available structures, by combining and recombining their building blocks (see also Marcus 2008 and Fitch 2010: 55, for a more recent reinforcement of this view). The proposal explored in this paper is also consistent with the Dependent Case Theory (e.g. Yip et al. 1987, Marantz 1991, Baker and Vinokurova 2010), where accusative and ergative cases are analyzed as dependent on the presence of another (first) argument (nominative and absolutive, respectively), making it plausible to reconstruct the first argument as the only argument in the ancestral grammar.

This demonstrates how formal, typological, and evolutionary considerations can be brought together in order to formulate specific and testable hypotheses which can address The Five Problems introduced in Section 2. In order to address The Selection and The Loop Problems more directly, the following sections explore the postulated approximations ("living fossils") of the ancestral grammar, their relevance for (sexual) selection, and their processing by the brain.

\section{Fossil compounds: The simplest possible verb-noun gram- mars}

There are several postulated types of approximations ("living fossils") of this stage found across modern languages, but the ones most closely approximating this grammar, as well as most directly interacting with biological considerations, are verb-noun compounds, as illustrated in e.g. English (6), Serbian 
(7), and Polish (8). These compounds tend to have transient lives, with many of them now obsolete, and with different generations being familiar with different ones. They specialize for insult/derogatory reference when referring to humans, and are often obscene/vulgar, depicting body functions and/or body parts.

English $^{8}$

kill-joy, turn-skin (cf. turn-coat), hunch-back, wag-tail, tattle-tale, scatter-brain, cutthroat, mar-wood (bad carpenter), heck-wood, busybody, cry-baby, break-back, catch-fly (plant), cut-finger (plant), fillbelly (glutton), lick-spit, pinch-back (miser), shuffle-wing (bird), skin-flint (miser), spit-fire, swish-tail (bird), stink-bug, tanglefoot (whiskey), tumble-dung (insect), crake-bone (crack-bone), shave-tail (shovetail), wipe-tail, wrynge-tail, fuck-ass, fuck-head, shit-ass, shithead

(7) Serbian $^{9}$

cepi-dlaka 'split-hair' (hair-splitter); guli-koža 'peel-skin' (who rips you off); vrti-guz 'spin-butt' (restless person, fidget); muti-voda 'muddy-water' (trouble-maker); jebi-vetar 'fuck-wind' (charlatan); vuci-guz 'drag-butt' (slow-moving person); gori-guzica 'burn-butt' (a person in trouble, cf. English burn-breeches); poj-kurić 'sing-dick' (womanizer); kosi-noga 'skew-leg' (person who limps); lezi-baba 'lie-old-woman' (loose woman or man); jedi-vek, 'eat-life' (one who constantly annoys); podvi-rep 'fold-tail' (one who is crestfallen); češi-guz 'scratch-butt'; deri-muda 'rip-balls' (place name, a steep hill); gladi-kur 'stroke-dick' (womanizer); piš-kur 'piss-dick'; kapi$k u r$ 'drip-dick' (name of a slow water spring); liz-guz 'lick-butt'; $n a-$ bi-guz 'shove-butt'; plači-guz 'cry-butt'; seri-vuk 'shit-wolf'

(8) Polish $^{10}$

chwali-bóg 'praise-god' (name); dusi-grosz 'squeeze-penny' (miser; cf. English pinch-penny); goli-broda 'shave-beard' (barber); hulajdusza 'roister-soul' (reveler); Kopaj-gród 'dig-town' (place name);

\footnotetext{
${ }^{8}$ Many additional English examples can be found in Weekley (1916).

${ }^{9}$ Many additional Serbian examples can be found in Mihajlović (1992).

${ }^{10}$ The Polish data were kindly supplied and/or glossed by Paweł Rutkowski (p.c. 2003).
} 
tami-strajk 'break-strike' (strike-breaker); łami-główka 'break-head. DIM' (puzzle, riddle); maci-woda 'muddy-water' (troublemaker, brawler; cf. Serbian muti-voda); moczy-morda 'soak-muzzle' (sot, drunkard); obieżyświat 'trot-world' (globe-trotter); pali-woda 'burnwater' (flibbertigibbet, madcap); pasi-brzuch 'pasture-belly' (glutton, lazybones); pędzi-wiatr 'drive-wind' (flibbertigibbet, madcap); rzezimieszek 'cut-purse' (pickpocket); wali-góra 'topplemountain' (giant of Polish folklore); wierci-pięta 'wiggle-heel' (fidget); wozi-woda 'carry-water' (water-carrier)

There are some striking generalizations to be made regarding these compounds, once one accumulates a critical mass of such data, especially data that span different languages (for many more details, and languages, see Progovac 2015). First, these compounds all consist of just one verb and one noun. ${ }^{11}$ Second, the noun is not specified grammatically as either subject-like or object-like. Third, the verbs and nouns used in these compounds tend to have concrete reference, but their combinations can describe rather abstract concepts, often exhibiting stunning feats of metaphorical creativity. Finally, these compounds specialize for derogatory reference and insult when referring to humans. Contrary to Nóbrega and Miyagawa's (2015) view, in order for these compounds to count as approximations ("living fossils") of early stages of syntax, they do not necessarily need to be found in every human language, with exactly the same characteristics (see Progovac 2013; 2019a,b for arguments against the assumption of uniformity of syntactic structure across all languages and constructions). Different languages in fact offer different types of fossillike structures in this sense, some rare to find across modern languages (Progovac 2015). The claim is that this is the starting point, the foundation upon which languages/cultures can build (or not) various types of syntactic complexity.

The emphasis here and elsewhere is on the term "approximation" in the relevant sense, as these present-day structures cannot be completely identical to the first attempts by our ancestors at grammatical combinations. For example, today's fossils utilize words which belong to morphosyntactic categories, i.e. nouns and verbs, and this distinction would not have been available

\footnotetext{
${ }^{11}$ For a discussion of how the verbs in these compounds in Serbian, and possibly in Polish, too, as well as in Romance languages, reveal some ancient imperative-like morphology, see Progovac (2015) and many references cited there.
} 
grammatically at the dawn of language. ${ }^{12}$ Nonetheless, these fossils approximate the postulated ancestral grammars in many crucial respects, including in that they lack transitivity and other layers of syntactic structure, such as vP, TP, CP, while still expressing basic predications using noun-like and verb-like items. These approximations, while not identical constructs, are no doubt at least as good proxies of the earliest stages of grammar as one can find among tools, cave paintings, or bird song.

The idea of syntactic living fossils comes from Jackendoff's work (1999, 2002) (see also Bickerton 1990), proposing that there are structures occurring in present-day languages which approximate ancestral language. Jackendoff considers compounds (e.g. snowman, scarecrow), as well as (other) loose combinations, e.g. adjunction, as good candidates for proto-syntactic fossils. Progovac (e.g. 2015, 2016a, 2019a) extends this idea to argument structure and sentences, arguing that these flat fossils are also built into the very foundation of hierarchical structures, including sentences. This is a stronger notion of fossil-hood, the one in which fossil structures live/survive not only next to modern structures, but also within them, as per the discussion of the hierarchical construct in (2). The importance of these proxies of early language cannot be overestimated, as they may be our best bet at advancing testable hypotheses regarding language/grammar evolution, which address all the five interlocking components, i.e. The Five Problems, introduced in Section 2. The next section outlines a specific scenario along these lines, which directly addresses The Selection and The Loop Problems, by using these proxies.

\section{Fossil compounds, verbal aggression, and sexual selection}

As discussed in Section 2, Subjacency is indeed not the kind of principle that would have led to fruitful sex, as sarcastically noted by Lightfoot (1991). But

\footnotetext{
${ }^{12}$ It has been reported that other primates are in principle capable of rudimentary two-slot combinations, such as hide peanut and hide Kanzi (see e.g. Greenfield and Savage-Rumbaugh 1990: 161, regarding bonobo Kanzi). According to Patterson and Gordon (1993), gorilla Koko is not only capable of producing novel two-slot metaphorical combinations (e.g. 'cookie rock,' for a stale bun), but also of insult, playfulness, and humor. Certainly, these are combinations in which one is not tempted to postulate a vP layer, or a grammatical distinction between nouns and verbs, and yet these combinations can be meaningful. Progovac (2017; also 2015) has argued that this is exactly where continuity of grammar should be sought, between these two-slot combinatorial abilities in primates (also found in some cases in the wild), and two-slot "fossils" in human languages.
} 
this is not because syntax is exempt from the messiness and baseness of (sexual) selection, but rather because Subjacency does not actually exist as a principle of syntax! So, perhaps after all, syntax/grammar is not such a lofty, dignified, and removed abstraction in our brains, but rather a capacity that started humble, by tinkering with the ability to combine just two basic, crude words, utilizing the simplest of syntax. At the point when grammar just started emerging, such combinations would have had an enormous adaptive value, which would have, in fact, been associated with fruitful sex.

In addition to many other beneficial uses of this kind of basic protogrammar, consider here just one kind of utility: creating vivid innovative insults with the crudest of proto-grammars, and the most basic of vocabulary. As proposed in Progovac and Locke (2009), coining compounds akin to the ones illustrated in the previous section would have been an adaptive way to compete for status and sex in ancient times. Their successful use would have enhanced relative status first by derogating existing rivals and placing prospective rivals on notice (intra-sexual selection), and second by demonstrating verbal skills and quick-wittedness to the opposite sex (inter-sexual selection). ${ }^{13}$ This two-slot grammatical strategy, among many other useful possibilities, would have led to a dramatic increase in the variety and creativity of insults, in comparison to a stage when only isolated words were used (see Progovac 2016a for a possible list of such proto-words, and how they significantly overlap with Swadesh lists of basic and shared crosslinguistic vocabulary, widely used in historical linguistics). This initial stage of proto-grammar would have unmasked, and thus opened for selection, the latent protolinguistic abilities of some of our ancestors, with which they were able to create novel expressions, never heard before, and to capture a trait of a person with only two basic proto-words. In Progovac and Benítez-Burraco (2019), we further hypothesize that looking at the (gradual) emergence of verbal means of aggression (approximated by this kind of compound) helps illuminate the initial steps of the language evolution/self-domestication feedback loop. By affording an adaptive (non-violent) way to compete for status and sex, these verbal items would have reinforced the effects of self-domes-

\footnotetext{
${ }^{13}$ Regarding intra-sexual selection, i.e. male-on-male competition, these compounds often describe men in derogatory terms, but even when they seemingly describe women (e.g. lezi-baba 'lie-old-woman', 'loose woman or man'), such compounds are still typically used to derogate men, for a doubly-insulting effect (Mihajlović 1992; Progovac and Locke 2009). According to e.g. Marsh (1978), the most common type of insult among men even in present times is the kind meant to emasculate the opponent.
} 
tication, by gradually replacing reactive physical aggression with verbal aggression.

Finally, with respect to the Loop Problem, this proposal predicts that these fossil structures are processed differently by the brain, in comparison with their hierarchical counterparts, which evolved later. In an fMRI experiment we contrasted the processing of verb-noun compounds (e.g. kill-joy; pick-pocket; cry-baby) vs. hierarchical compounds (e.g. joy-kill-er; boot-licker; whistle-blow-er) and found a robust effect in the fusiform gyrus area (BA 37) (Progovac et al. 2018b), the area where visual processing and certain non-compositional semantic processing (e.g. concreteness, metaphor) come together (e.g. Bookheimer 2002). More precisely, we found more activation in BA 37 for fossil compounds, when compared to hierarchical compounds.

Surprisingly, fossil compounds seem to evoke a more vivid, more visceral effect than their hierarchical -er counterparts, even though the latter were matched in imageability/metaphoricity of the vocabulary used (e.g. joy-killer; boot-lick-er; whistle-blow-er). One possible explanation is that the layer(s) of abstract syntactic structure render these hierarchical compounds less visceral/imageable. Section 7 reports results of additional fMRI experiments testing the processing of additional fossils, and draws conclusions regarding the import and potential of such testing.

\section{Fossil middles, split-accusativity, and the processing of the two grammar types}

Here I consider another potential fossil structure, found among so-called middles, available in Slavic languages, but also in Romance and elsewhere (Kemmer 1994). Slavic se presents several enigmas for linguistic analysis, including (i) that it has a wide and overlapping range of functions/meanings (10a); (ii) that it cannot really be analyzed as a reflexive pronoun (9a, 10a, 11); and (iii) that it occasionally involves first person interpretations, without any first person morpho-syntactic marking (11a, 12) (see e.g. Kański 1986: 195; Rivero and Milojević-Sheppard 2003, for Polish). Considering especially $(9 \mathrm{a}, 10 \mathrm{a}, 11 \mathrm{a})$, it would not make much sense to analyze se as a reflexive pronoun, at least not in Serbian. These (a) examples in (9-11) contrast sharply with their (b) counterparts, which feature a true reflexive pronoun sebe, yielding unambigiously reflexive readings, and only reflexive readings (comparable to English -self forms). 
(9a) Pas se ujeda. (vague; dispreferred reflexive reading) dog SE bites

'The dog bites (someone).'

'??The dog is biting itself.'

(9b) Pas ujeda sebe REFL. 'The dog is biting itself.'

(unambiguous reflexive)

(10a) Žen se čuju. (vague) womenNOM SE hear3PL

'(The) women hear themselves.'

'(The) women hear each other.'

'One can hear (the) women.'

'Women get heard.' (e.g. because they are loud, persistent, etc.)

(10b) Žene čuju sebe $\mathrm{REFL}_{\text {. }}$ (unambiguous reflexive) '(The) women can hear themselves.'

(11a) Marko se gura! (vague; dispreferred reflexive reading) Marko SE pushes

'Marko is pushing me/us.'

'Marko is pushing somebody.'

'???Marko is pushing himself.'

(11b) Marko gura sebe REFL. (unambiguous reflexive, even if odd) '??Marko is pushing himself.'

(12) Nie pchaj się pan! (Polish)

not push SE man

'Stop pushing (me), man!'

Where pragmatics permits, Serbian se middles reveal their vagueness, ranging over passive-like, middle-like, reflexive-like, reciprocal, and other interpretations. These constructions are analyzed in Progovac (2015) as vP-less, absolutive-like, one-argument structures, which resemble verb-noun compounds of Section 5 in that they also fail to distinguish grammatically between subjects/agents and objects/patients. This can be expected of a grammar which has space for only one single argument. This general analysis is 
the only way to provide a unified account of se in its various manifestations in Serbian. It is the vagueness of these se constructions that frees them to interplay with the point of view of the speaker, giving rise to pragmatically salient first person interpretations, which are otherwise impossible to explain $(11,12)$.

Semantically, these structures are best analyzed as featuring one unspecified thematic role of a proto-participant (see e.g. Dowty 1991 for protoroles), where (13) is the proposed semantic representation of (10a), and (14) the representation of (12). With the semantics in (14), nothing prevents (12) from taking the pragmatically salient first person to be the patient of the event, given that the patient of these otherwise transitive verbs is not supplied grammatically/linguistically.

$$
\exists \mathrm{e}[\mathrm{H}(\mathrm{e}) \wedge \text { Participant (Women,e) }]
$$

$$
\exists \mathrm{e}[\mathrm{P}(\mathrm{e}) \wedge \text { Participant }(\text { You,e })]
$$

It is of note that Tongan intransitive (4a), repeated below from Section 4, also features one single absolutive argument, leading to vagueness comparable to what is found in Serbian middles, as well as in verb-noun compounds: all these structures feature just one verb and one argument, not grammatically specified as either subject or object. The absolutive role in ergative languages is (in)famous for its lack of specialization for either subject-like or objectlike roles. As emphasized in Tchekhoff (1973: 283), the absolutive argument Mary in (4a) is neither an agent nor a theme, and the two translations just reflect a nominative-accusative bias. Instead, "Mary is the only determiner [i.e. argument, LP], and the whole utterance gives us only the following information: present tense, verb call, Mary..." Tchekhoff (1973: 283). As such, Tongan (4a) is best analyzed as involving an unspecified proto-participant semantics (15), directly comparable to that proposed for Serbian middles in (13).

(4a) Oku ui 'a Mele

PRES call ABS Mary

'Mary calls.' / 'Mary is called.'

$\exists \mathrm{e}[\mathrm{C}(\mathrm{e}) \wedge$ Participant (Mary,e) $]$ 
While nom-acc patterns are certainly the dominant (default) grammar in Serbian, (absolutive-based) se middles are productive and rather common. If so, then se can be seen as flagging a different, parallel type of grammar in Serbian (ergative-absolutive), suggesting that Serbian may be a split-accusative language, on analogy with split-ergative languages. In Nichols et al.'s (2004) typology, Serbian would be classified as a detransitivizing language, with se serving as a detransitivizer.

Even though there is overlap between the two grammars, there is also, to some extent, a division of labor, with se middles proving especially wellsuited for expressing low-elaboration of events (e.g. low animacy (16-17); anti-causativity (16); reflexivity). On the other hand, accusative grammar is better suited for expressing high elaboration of events in Serbian. Especially noteworthy is the contrast between absolutive-like middles ( $a, b$ examples below), which exhibit animacy effects, and the (default) accusative grammars, illustrated in the (c) examples, which do not show such effects.

(16a) Prozor se razbio.

(middle, inanimate)

'(The) window broke.'

(16b) *Golman se razbio.

(middle, highly animate)

??'(The) goalie broke/shattered.'

(16c) Razbili su golmana/prozor. (accusative, animate/inanimate)

'(They) broke (the) goalie/windowACC.'

(17a) Meso/pile se pojelo. (middle, lower animacy)

'(The) meat/chicken got eaten.'

(17b) ???Lav se pojeo.

'(The) lion got eaten (by e.g. hyenas).'

(17c) Pojeli su lava/pile/meso. (accusative, animate/inanimate) '(They) ate (the) lion/chicken/meat ${ }_{\mathrm{ACC}}$.'

Consistent with this analysis, absolutive-like se structures seem to be processed differently by the brain, in comparison to transitive accusative struc- 
tures. Progovac et al. (2018a) report the results of an fMRI experiment which was designed to test the processing of $\mathrm{vP}$-less se middles in Serbian, in comparison to their semantically matched accusative counterparts with vP. We specifically looked at the differential role played by the Broca's-basal ganglia network in processing ancestral versus more modern types of structures because several recent findings suggest that this network has been bolstered relatively recently in evolution, through selection, by increased synaptic plasticity and neuronal connectivity (e.g. Ullman 2006; Dediu 2015; Hillert 2014).

We hypothesized that the processing of Serbian middles, relative to (phonologically and semantically) matched transitive accusative counterparts, would result in reduced activation in the Broca's-basal ganglia network (Progovac et al. 2018a). We found that the processing of transitives, compared to middles, indeed showed an increase in activation in the basal ganglia bilaterally. While we did not find a contrasting effect in Broca's area, we found that transitives, contrasted with middles, evoked greater activation in the precentral gyrus (BA 6), proposed to be part of the "Broca's complex" (Ardila et al. 2016). In a related fMRI experiment (Progovac et al. 2018b), we tested the processing of English full sentences with TPs (e.g. The case is closed; The apology is accepted), contrasted with TP-less small clauses (Case closed; Apology accepted), and found a significant difference in both Broca's left BA 44 and right basal ganglia for full (TP) sentences vs. (TPless) small clauses, affirming the relevance of Broca's-basal ganglia network for the processing of more articulated, layered syntax. This also demonstrates that the consideration of these vP-less and TP-less structures as approximations of ancestral grammars is on the right track, and that it affords unique and direct ways of subjecting evolutionary proposals to empirical testing, addressing the language-brain-genes loop (The Loop Problem).

These findings are compatible with the view that the pressures to master certain language abilities were at least partly responsible for driving the selection processes which increased the connectivity of the Broca's-basal ganglia network. At the very least, these experiments show that the postulated fossil structures are processed differently by the brain, and that there is tangible syntactic variability even within single languages, which provides fertile ground for hypothesizing and testing proposals regarding language evolution. The gradualist approach to the evolution of syntax pursued here views syntax less as a precise mathematical formula, but more like a colorful quilt, seamlessly stitched together from a variety of pieces and patterns accrued at 
various junctures in language evolution (Progovac 2016b). ${ }^{14}$ This is also how geneticists describe the human genome: as "a patchwork quilt ... with segments that were picked up at different stages of our ancestry" (Harris 2015: xvii). By considering a variety of languages and their grammar quilts with "fossils" stitched into them, and by subjecting them to both theoretical analysis and a variety of experiments, we stand a good chance at finding some critical answers to the question of how language evolved. It is often claimed that language does not fossilize, and that for that reason we can never figure out its evolution. There is no doubt that the fossils of language will not be literally dug up from some archeological site, but, if this proposal is on the right track, then linguistic fossils, i.e. proxies of early linguistic stages, are even much more accessible and available than any other type of fossil. Just as genetic quilts provide clues to the evolution of the species, so does the variability of syntactic structures found both within and across languages. But these postulated fossils now need to be unstiched and unhinged from the complex quilts that are human languages, using linguistic theories and experimental methods as tools, rather than chisels.

\section{References}

Aboh, E. 2009. Clause structure and verb series. Linguistic Inquiry 40.1-33.

Adger, D. 2003. Core syntax: A minimalist approach. Oxford: Oxford University Press.

Ardila, A., B. Bernal and M. Rosselli. 2016. Why Broca's area damage does not result in classical Broca's aphasia? Frontiers in Human Neuroscience 10.

Baker, M. C. and N. Vinokurova. 2010. Two modalities of Case assignment: Case in Sakha. Natural Language and Linguistic Theory 28. 593-642.

Belletti, A. and L. Rizzi. 2000. An interview on minimalism, with Noam Chomsky. The University of Siena, November 8-9, 1999. Revised 16 Mar 2000. $<$ http://www.media.unisi.it/ciscl/pubblicazioni.htm>

Bergen, B. K. 2016. What the F: What swearing reveals about our language, our brains, and ourselves. New York: Basic Books.

Berwick, R. and N. Chomsky. 2011. The biolinguistic program. The current state of its development. In A. M. Di Sciullo and C. Boeckx (eds.), The biolinguistic en-

\footnotetext{
${ }^{14}$ This of course assumes that we syntacticians, especially those working within Minimalism, need to abandon the frequent assumption that syntax is uniform across all constructions and all languages. This assumption has proven to be a true hinderance to studying the evolution of syntax, and language more generally, in addition to generating a host of unfalsifiable claims in syntactic theory itself (for more discussion, see Progovac 2013; 2019b).
} 
terprise: New perspectives on the evolution and nature of the human language faculty. 19-41. Oxford: Oxford University Press.

Berwick, R. and N. Chomsky. 2016. Why only us? Language and evolution. Cambridge, MA: The MIT Press.

Bickerton, D. 1990. Language and species. Chicago: University of Chicago Press.

Bickerton, D. 2007. Language evolution: A brief guide for linguists. Lingua 117. 510-526.

Bookheimer, S. 2002. Functional MRI of language: New approaches to understanding the cortical organization of semantic processing. Annual Review of Neuroscience 25. 151-188.

Chomsky, N. 1995. The Minimalist Program. Cambridge, MA: MIT Press.

Chomsky, N. 2002. On nature and language. (Edited by Adriana Belletti and Luigi Rizzi.) Cambridge: Cambridge University Press.

Citko, B. 2011. Symmetry in syntax: Merge, Move, and labels. Cambridge: Cambridge University Press.

Darwin, C. M. A. 1874. The descent of man, and selection in relation to sex. (New edition.) New York: Hurst and Company.

Deacon, T. W. 2003. Multilevel selection in a complex adaptive system: The problem of language origins. In W. H. Bruce and D. J. Depew (eds.), Evolution and learning: The Baldwin effect reconsidered. (A Bradford Book.) 81-106. Cambridge, MA: The MIT Press.

Dediu, D. 2015. An Introduction to genetics for language scientists. Cambridge: Cambridge University Press.

Dowty, D. 1991. Thematic proto-roles and argument selection. Language 67(3). 547619.

Fitch, W. T. 2010. The evolution of language. Cambridge: Cambridge University Press.

Fitch, W. T. 2017a. Preface to the special issue on the biology and evolution of language. Psychonomic Bulletin Review 24. 1-2.

Fitch, W. T. 2017b. Empirical approaches to the study of language evolution. Psychonomic Bulletin Review 24. 3-33.

Franks, B. and K. Rigby. 2005. Deception and mate selection: Some implications for relevance and the evolution of language. In M. Tallerman (ed.), Language origins: Perspectives on evolution. 208-229. Oxford: Oxford University Press.

Gleeson, B.T. 2018. Masculinity and the mechanisms of human self-domestication. BioRxiv preprint.

Greenfield, P. M. and S. Savage-Rumbaugh. 1990. Language and intelligence in monkeys and apes. In S. T. Parker and K. R. Gibson (eds.), Grammatical combination in Pan paniscus: Process of learning and invention in the evolution and development of language. 540-579. Cambridge: Cambridge University Press.

Hare, B., V. Wobber and R. Wrangham. 2012. The self-domestication hypothesis: Evolution of bonobo psychology is due to selection against aggression. Animal Behavior 83(3). 573-585.

Harris, E. E. 2015. Ancestors in our genome: The new science of human evolution. Oxford: Oxford University Press. 
Heine, B. and T. Kuteva. 2007. The genesis of grammar. A reconstruction. Oxford: Oxford University Press.

Hill, A. K., D. H. Bailey and D. A. Puts. 2017. Gorillas in our midst? Human sexual dimorphism and contest competition in men. In F. J. Ayala (ed.), On human nature. 235-249. San Diego: Academic Press.

Hillert, D. 2014. The nature of language: Evolution, paradigms and circuits. New York: Springer.

Jackendoff, R. 1999. Possible stages in the evolution of the language capacity. Trends in Cognitive Science 3. 272-279.

Jackendoff, R. 2002. Foundations of language: Brain, meaning, grammar, evolution. Oxford: Oxford University Press.

Jacob, F. 1977. Evolution and tinkering. Science 196. 1161-1166.

Kański, Z. 1986. Arbitrary reference and reflexivity: A generative study of the Polish pronoun się and its English equivalents. Katowice: Uniwersytet Śląski.

Kemmer, S. 1994. Middle voice, transitivity, and the elaboration of events. In B. Fox and P. J. Hopper (eds.), Voice: Form and function. Amsterdam: John Benjamins, 179-230.

Kitagawa, Y. 1985. Small but clausal. Chicago Linguistic Society 21. 210-220.

Lightfoot, D. 1991. Subjacency and sex. Language \& Communication 11. 67-69.

Locke, J. L. 2009. Evolutionary developmental linguistics: Naturalization of the faculty of language. Language Sciences 31. 33-59.

Marantz, A. 1991. Case and licensing. In G. Westphal, B. Ao and H.-R. Chae (eds.), Proceedings of the 8th Eastern States Conference on Linguistics (ESCOL 8). 234-253. Ithaca, NY: CLC Publications.

Marcus, G. 2008. Kluge: The Haphazard Construction of the Human Mind. Boston and New York: Houghton Mifflin Company.

Marsh, P. 1978. Aggro: The illusion of violence. London: Dent.

Mihajlović, V. 1992. Ime po zapovesti [Name by Command]. Beograd: Nolit.

Miller, G. A. 2000. The mating mind: How sexual choice shaped the evolution of human nature. London: William Heinemann.

Müller, F. M. 1861. The theoretical stage, and the origin of language. Lectures on the science of language. London: Longman, Green, Longman, and Roberts.

Newmeyer, F. J. 1991. Functional explanation in linguistics and the origin of language. Language and Communication 11. 1-28.

Nichols, J., D. A. Peterson and J. Barnes. 2004. Transitivizing and detransitivizing languages. Linguistic Typology 8. 149-211.

Nóbrega, V. and S. Miyagawa. 2015. The precedence of syntax in the rapid emergence of human language in evolution as defined by the integration hypothesis. Frontiers in Psychology. DOI.org/10.3389/fpsyg.2015.00271.

Okanoya, K. 2015. Evolution of song complexity in Bengalese finches could mirror the emergence of human language. Journal of Ornithology 156(1). 65-72.

Patterson, F. and W. Gordon, W. 1993. The case for the personhood of gorillas. In P. Cavalieri and P. Singer (eds.), The great ape project. 58-77. New York, NY: St. Martins Griffin.

Progovac, L. 2009. Sex and syntax: Subjacency revisited. Biolinguistics 3(2-3). 305336. 
Progovac, L. 2013. Nonsentential vs. ellipsis approaches: Review and extensions. Language and Linguistics Compass 7/11. 597-617.

Progovac, L. 2015. Evolutionary syntax. (Oxford Studies in the Evolution of Language.) Oxford: Oxford University Press.

Progovac, L. 2016a. A gradualist scenario for language evolution: Precise linguistic reconstruction of early human (and Neandertal) grammars. Frontiers in Psychology 7.1714. DOI: 10.3389/fpsyg.2016.01714.

Progovac, L. 2016b. Review of Robert Berwick and Noam Chomsky's 2016 book Why only us: Language and evolution. Cambridge, MA: Cambridge University Press. Language 92(4). 992-996.

Progovac, L. 2017. Where is continuity likely to be found? Commentary on 'The social origins of language' by Robert M. Seyfarth and Dorothy L. Cheney. Edited and introduced by Michael Platt. Princeton and Oxford: Princeton University Press. 46-61.

Progovac, L. 2019a. A Critical Introduction to Language Evolution: Current Controversies and Future Prospects. Springer Expert Briefs in Linguistics. Switzerland: Springer.

Progovac, L. 2019b. Minimalism in the light of biology: What to retain and what to discard? Frontiers in Psychology 10.1303. DOI: 10.3389/fpsyg.2019.01303.

Progovac, L., and A. Benítez-Burraco. 2019. From physical aggression to verbal behavior: Language evolution and self-domestication feedback loop. Frontiers in Psychology 10: 2807. doi: 10.3389/fpsyg.2019.02807.

Progovac, L. and J. L. Locke. 2009. The urge to merge: Ritual insult and the evolution of syntax. Biolinguistics 3(2-3). 337-354.

Progovac, L., N. Rakhlin, W. Angell, R. Liddane, L. Tang and N. Ofen. 2018a. "Diversity of grammars and their diverging evolutionary and processing paths: Evidence from functional MRI study of Serbian. Frontiers in Psychology 9.278. (Special issue: Languages as adaptive systems, edited by E. Aboh and U. Ansaldo.)

Progovac, L., N. Rakhlin, W. Angell, R. Liddane, L. Tang and N. Ofen. 2018b. Neural correlates of syntax and proto-syntax: An fMRI study. Frontiers in Psychology 9.2415. 1-16. DOI: 10.3389/fpsyg.2018.02415.

Rivero, M.L. and M. Milojević-Sheppard. 2003. "(Indefinite) reflexive clitics in Slavic: Polish and Slovenian. Natural Language and Linguistic Theory 21. 89155.

Ross, J. R. 1967. Constraints on variables in syntax. (Cambridge, MA: Massachusetts Institute of Technology PhD Dissertation.)

Stanyon, R. and F. Bigoni. 2014. Sexual selection and the evolution of behavior, morphology, neuroanatomy and genes in humans and other primates. Neuroscience \& Biobehavioral Reviews 46(4). 579-590.

Steels, L. 2011. Modeling the cultural evolution of language. Physics of Life Reviews 8. 339-356.

Stone, L. and P. F. Lurquin. 2007. Genes, culture, and human evolution: A synthesis. Blackwell Publishing.

Stowell, T. 1983. Subjects across categories. The Linguistic Review 2/3. 285-312. 
Tallerman, M. 2013. Kin selection, pedagogy, and linguistic complexity: Whence protolanguage? In R. Botha and M. Everaert (eds.), The evolutionary emergence of language. 77-96. Oxford: Oxford University Press.

Tchekhoff, C. 1973. Some verbal patterns in Tongan. The Journal of the Polynesian Society 82(3). 281-292.

Toya, G. and T. Hashimoto. 2015. Computational study on evolution and adaptability of recursive operations. The 20th (AROB) International Symposium on Artificial Life and Robotics. Beppu, Japan. 68-73.

Ullman, M. T. 2006. Is Broca's area part of a basal ganglia thalamocortical circuit? Cortex 42. 480-485.

Van Leynseele, H. 1975. Restrictions on serial verb constructions in Anyi. Journal of West African Languages X. 189-217.

Weekley, E. 1916. Surnames. New York: E.P. Dutton and Co.

Yip, M., J. Maling and R. Jackendoff. 1987. Case in tiers. Language 63. 217-250.

Corresponding author:

Ljiljana Progovac

Linguistics Program

Department of English

Wayne State University

5057 Woodward

Detroit, MI 48202

United States

progovac@wayne.edu 